\title{
Estratégia de ensino-aprendizagem planejada: uma opção docente para estimular o discente a compreender regras e variações da língua portuguesa ${ }^{1}$
}

\author{
Dieysa Kanyela Fossile
}

\begin{abstract}
Resumo: Para demonstrar a importância de estratégias de ensino-aprendizagem planejadas para o ensino da Língua Portuguesa, apresenta-se, neste artigo, uma investigação relacionada à questão da imposição das normas gramaticais nas aulas de Língua Portuguesa. Trata-se de um estudo exploratório

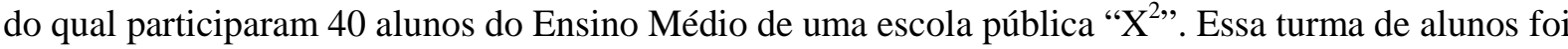
dividida em dois grupos: grupo A e grupo B. O grupo A desenvolveu práticas de estudos referentes à linguagem padrão e às suas variações, isto é, coletou e analisou a fala de 50 habitantes do município de São Francisco do Sul - (SC). O grupo B, por sua vez, não desenvolveu essas práticas de estudo. Os resultados sugerem que a estratégia de ensino aplicada e desenvolvida com os alunos do grupo A contribuiu para estimular o aprender a compreender a língua em uso. Portanto, concluiu-se que é de extrema importância que os futuros profissionais dessa área de ensino sejam orientados sobre a importância de estratégias de ensino-aprendizagem diferenciadas, planejadas e que correspondam à realidade do aluno.
\end{abstract}

Palavras-chave: Formação docente; estratégias de ensino-aprendizagem; aulas de Língua Portuguesa.

\begin{abstract}
To demonstrate the importance of the planned learning-teaching strategies to the Portuguese language teaching, it presents, in this article, a research related to the imposition issue of grammatical rules in the Portuguese Language classes. It is about an explanatory study in which participated 40 high school students from a public school " $\mathrm{X}^{2}$ " "This group of students was divided into two groups: A group and B group. The A group has developed study practices related to a standard language and its variation, in other words, collected and analyzed the speech of 50 inhabitants from "São Francisco do Sul” city - (SC). The B group, on the other hand, has not developed those study practices. The results suggest that the teaching strategy applied and developed with the A group students contributed to stimulate the learning and comprehension of the language in use. Therefore, it concluded that it is really important to the future professionals of that teaching area to be orientated towards the importance of the planned and differentiated learning-teaching strategies to correspond to the student reality.
\end{abstract}

Key-words: Teaching formation; learning-teaching strategies; Portuguese Language classes. 


\section{Introdução}

Este artigo tem como objetivo principal abordar que professores de língua portuguesa durante a sua formação devem ser preparados e alertados sobre o quão importante é buscar estratégias de ensino-aprendizagem para que um aluno possa aprender a compreender a língua portuguesa, no que se refere ao ensino de gramática. É importante que os profissionais dessa área sejam preparados para que um aluno tanto do ensino fundamental quanto do ensino médio,

(a) desenvolva sua capacidade de uso da linguagem em várias situações;

(b) amplie sua capacidade de compreensão de textos em geral, interpretando-os e analisando-os de forma crítica e reflexiva;

(c) saiba lidar com os variados textos encontrados no meio social;

(d) compreenda e respeite as variedades linguísticas que existem no meio social;

(e) encare a linguagem como meio de ter acesso aos conhecimentos indispensáveis para a vida em sociedade.

De acordo com Silva (2005, p. 236), há diversas crenças em relação ao ensino e à aprendizagem de línguas, que têm estimulado vários pesquisadores (BARCELOS e VIEIRAABRAHÃO, 2006; ROCHA, 2006; GARBUIO, 2005; GIL, RAUBER, CARAZZAI e BERGSLEITHNER, 2005, SILVA, 2005; dentre outros) e, para demonstrar a importância de profissionais preparados e preocupados com o ensino da língua portuguesa, desenvolveu-se, em 2002, o projeto de iniciação científica intitulado "Linguagem padrão: uma forma de subjugar"”. Em 2003, desenvolveu-se o projeto de iniciação científica “Problemas de sintaxe e ortografia: análise de produções textuais do ensino fundamental e médio" ${ }^{4}$. Os dois projetos foram desenvolvidos na Universidade da Região de Joinville - (UNIVILLE). A partir desta iniciativa até os dias atuais esta investigação não teve mais fim, sendo sempre atualizada, pois uma boa formação profissional na área da língua portuguesa é de extrema importância para a educação. 
Neste caso, apresenta-se neste artigo, uma atividade(estratégia d e ensinoaprendizagem planejada). Para isso, foi organizado um grupo de quarenta alunos do terceiro ano do Ensino Médio da Escola de Educação Básica “X” do município de São Francisco do Sul - SC. O grupo foi dividido em: Grupo A (composto por vinte alunos - Alunos pesquisadores) e Grupo B (Composto por vinte alunos - Alunos não pesquisadores). No primeiro grupo, o professor $\mathrm{Y}^{5}$ agiu de maneira interativa, quer dizer, o professor interagiu ativamente com os alunos, isto é, discutindo, questionando, debatendo sobre dados assuntos que eram abordados durante a aula, por meio dessa atitude o professor passou a estimular o instinto pesquisador, o senso crítico e reflexivo dos alunos, nunca impôs nenhum conteúdo. No segundo grupo, o mesmo professor agiu como um transmissor de conteúdos, isto é, não interagiu ativamente com os alunos, apenas transmitiu e explicou conteúdos.

O grupo A desenvolveu estudos (cf. seção 2 e seção 3 deste artigo) referentes à linguagem padrão e às suas variações, coletando a fala de cinquenta habitantes do município citado. Eles se reuniam para realizar a análise e a transcrição das falas coletadas, comparandoas à Gramática Tradicional. Por meio desta investigação, concluíram que existe uma linguagem padrão ligada às regras gramaticais que todos os falantes devem dominar, notaram também que existem formas variantes dentro da linguagem padrão que não podem ser julgadas como pobres, nem erradas, mas devem ser entendidas como diferentes. O grupo percebeu que as formas variantes referiam-se, principalmente, à concordância verbal, à concordância nominal, à regência verbal. Além desses fatores citados, os alunos identificaram reduções e acréscimos fonéticos, bem como a troca de fonemas. Nesse grupo, o professor Y agiu de forma interativa, desempenhou o papel de mediador entre o meio e os alunos. Já o grupo B não participou da pesquisa (coleta de falas, transcrição e análise das falas coletadas, comparação das falas coletadas com as regras da Gramática Tradicional), embora tenham sido transmitidas a esse grupo noções gramaticais normativas e, em dados momentos, noções de variedades linguísticas observou-se que não compreenderam que a Língua Portuguesa é uma disciplina que abre espaço para a discussão e para a reflexão, pois não estudaram, não observaram, não analisaram as regras gramaticais normativas e nem as variedades linguísticas de forma reflexiva e crítica, apenas teórica. Nesse grupo, o professor Y apenas transmitiu a matéria (regras gramaticais da Língua Portuguesa) ao aluno.

Com relação à organização deste artigo, nas próximas seções, apresentam-se algumas considerações sobre o ensino de gramática, a linguagem padrão e suas variações. Em seguida, descreve-se a metodologia (atividade desenvolvida com os alunos do grupo A e do grupo B, 
com base numa estratégia de ensino planejada) e, por fim, apresentam-se e discutem-se os principais resultados.

\section{Gramática Tradicional: uma certa imposição}

Todas as pessoas possuem capacidade de aprender a falar, é só observarmos as crianças, elas “[...] conseguem domínio da língua falada antes de aprenderem a ler e escrever e conseguem-no espontaneamente, sem qualquer treinamento [...]” (LYONS, 1973, p. 20). Desde os primórdios, a Gramática Tradicional é imposta à sociedade e ainda continua sendo, como se fosse algo estático e único. De acordo com Bagno (1999, p. 15)

esse mito é prejudicial à educação porque, ao não reconhecer a verdadeira diversidade do português falado no Brasil, a escola tenta impor sua norma lingüística como se fosse de fato, a língua comum a todos os [...] brasileiros, independente de sua idade, de sua origem geográfica, de sua situação socioeconômica, de seu grau de escolarização etc.

A linguagem ensinada e cobrada nas escolas tem acentuada relação com o domínio social. Muitas vezes, um indivíduo é bem aceito socialmente se dominar os requisitos da gramática normativa. Mussalim e Bentes (2001, p. 255) sustentam que, na maioria dos casos, esse "preconceito contra a língua mistura-se ao preconceito contra o usuário da língua”. Parece que um determinado pré-julgamento está em vigor no mundo escolarizado. Seres humanos são submetidos a este julgamento desde cedo. Já na escola é desenvolvida uma classificação, isto é, o aluno é julgado como ser capaz ou incapaz, culto ou inculto, devido ao seu comportamento linguístico. O comportamento de uma criança de classe média baixa e o comportamento de uma criança de classe alta pode apresentar diferenças que podem estar associadas ao meio em que ela vive. Não se pode, contudo, confundir deficiência com diferença, pois cada qual está submetido a sua origem cultural e às suas raízes familiares. É o que Orlandi (1985, p. 07) propõe quando relata que "o homem procura dominar o mundo em que vive [...] e a linguagem é uma dessas coisas”. O mundo em que se vive é organizado na perspectiva da dominação. O indivíduo que não apresentar certo domínio linguístico tanto na oralidade quanto na escrita é, muitas vezes, excluído e discriminado pela sociedade, sendo julgado como "um ser sem língua [...] como uma pessoa que tem uma língua pobre, pouco desenvolvida” (MANDRIK \& FARACO, 2001, p. 225). De acordo com Bagno (1999, p. 
139), “por mais que isso nos entristeça ou irrite é preciso reconhecer que o preconceito lingüístico está aí firme e forte”.

Ressalta-se que neste artigo não se deseja fazer alusão a ideia de que as regras gramaticais não devem ser ensinadas na escola, muito pelo contrário, objetiva-se ressaltar que o ensino das regras gramaticais deve ser realizado, ou seja, os alunos devem ser informados sobre a existência de tais regras, porém a maneira como tal ensino é realizado é que deve ser analisada, pensada, estudada e planejada com cuidado.

Mandrik e Faraco (2001, p. 250) sustentam que a

[...] linguagem padrão, [...] não deve ser entendida como algo cristalizado, excessivamente artificial, como é costume na escola. A língua é um fato em permanente mudança e, por isso, não devemos esperar que as pessoas no fim do século XX falem a variedade padrão do século XVI ou do século XIX. Temos de aceitar [...] formas variantes dentro da padrão.

E isto deve ser transmitido aos alunos pelos professores de língua portuguesa. Pois devido à falta desta explicação há, em dados momentos, um alto índice de rejeição em relação ao estudo da gramática, ou melhor, à disciplina da língua portuguesa em relação às outras disciplinas, mesmo porque se acredita que a gramática não abre espaço para explicação ou pesquisa e, sim, crê-se que a gramática é algo pronto que só se aprende decorando. Diante desses fatos, apresenta-se a seguinte questão: se um professor de história disser

[...] a seus alunos que, no século XVI, a região onde vivemos era ocupada por povos indígenas [...] e um aluno [...] perguntar: Professor, como [...] sabe disso? [...] o professor deve ter meios de responder; ele pode alegar que os documentos da época [...] atestam a presença dos índios, escavações [...] etc. O importante a observar é: o aluno tem o direito de fazer aquela pergunta, e o professor tem o dever de responder, ou pelo menos tentar responder [...]. Mas, em gramática, as coisas costumam ser diferentes. O professor diz que o futuro do subjuntivo do verbo ver é quando eu te vir [...]. O aluno sabe [...] que ninguém fala assim, [...] dizemos quando eu te ver ... Em outras palavras, o que o professor está ensinando não bate com o que se observa na realidade. Se um aluno perguntar por que o professor está dizendo que a forma é quando eu vir, a resposta (se houver resposta) será que é assim que é o certo. Note-se: não se deu nenhum motivo racional, deu-se uma ordem: faça assim [...] (PERINI, 1997, p. 51).

Tal fato leva a pensar que as escolas em parceria com os seus professores deveriam planejar estratégias de ensino que não ditem e nem imponham regras gramaticais aos alunos, 
mas que incentivem os alunos a buscarem por respostas sobre as regras gramaticais e as variações linguísticas existentes. Este exercício não só promoveria o “[...] desenvolvimento de uma habilidade e de um hábito de falar, de verbalizar, mas ainda de reflexão, de formulação de idéias, sobre a própria atividade lingüística”, tal como defende Bechara (1989, p. 46).

Porém, infelizmente, a Gramática Tradicional ainda detém larga influência. Bagno (2000, p. 26) advoga que

as gramáticas normativas brasileiras permanecem apegadas ao mito da língua única e se apresentam como descrição de uma variedade lingüística supostamente empregada pelas pessoas cultas do país, isto é, pelas classes dominantes apresentando-a sempre como o padrão a ser imitado. Daí nasce o preconceito de que toda e qualquer variedade diferente dessa é feia, estropiada, corrompida e não é raro escutar que isso não é português. Cria-se assim uma entidade abstrata Língua Portuguesa.

As noções de certo e errado que muitas vezes são transmitidas aos alunos nas aulas de língua portuguesa deveriam ser substituídas pelas noções de adequado e inadequado. Desta forma, segundo Leite e Silveira (1980, p. 19) “o aluno se sentirá menos tolhido de expressarse, oralmente ou por escrito, [...] se estiver consciente de que o que costuma falar ou escrever [...] não está errado [...] mas inadequado a certas situações [...] formais”.

Bagno (2000, p. 30) sustenta que no mundo social atual ainda existe uma inversão entre escrita e fala. Ele aborda que muitos ainda acreditam que se deve falar de acordo com a escrita, isto é, “a forma gráfica das palavras é que nos deve guiar no momento de pronunciálas, a língua oral é que deve 'respeitar' a ortografia, enquadrar-se em seus moldes, caber na roupagem gráfica, e não o contrário ...”. Bagno (2001) advoga que a língua falada não é a língua escrita, a língua falada é natural e a ortografia (escrita) é artificial. Ele sustenta que um bom desenvolvimento ortográfico exige exercícios de memorização e treinamento. O autor argumenta que escrever é uma competência que tem que ser aprendida como dirigir um carro, tocar piano, dançar, andar de bicicleta, etc.

Para que o professor possa atingir efetivamente seus objetivos, é necessário que realize um conjunto de operações didáticas coordenadas entre si. São o planejamento, a direção do ensino e da aprendizagem e a avaliação, cada uma delas desdobrada em tarefas ou funções didáticas, mas que convergem para a realização do ensino propriamente dito, ou seja, a direção do ensino e da aprendizagem (LIBÂNEO, 1992, p. 72). 


\section{Metodologia: estratégia de ensino planejada}

A partir do referencial teórico descrito, pode-se perceber que estratégias de ensinoaprendizagem planejadas são necessárias para o desenvolvimento de uma aprendizagem significativa ao aluno. Portanto, pensando nessa questão, desenvolveu-se este estudo em que se objetivou buscar uma nova perspectiva em relação ao ensino-aprendizagem da gramática e da variação linguística, desvinculada de práticas pedagógicas que ensinam português impondo-o como um conjunto interminável de regras gramaticais (únicas) - “consideradas corretas”. Tal como já apresentado na introdução deste artigo, esta pesquisa foi dirigida a uma turma de quarenta alunos do $3^{\circ}$ ano do Ensino Médio da Escola de Educação Básica "X”. Esta turma foi dividida em:

- Grupo A: Composto por vinte alunos - Alunos pesquisadores.

- Grupo B: Composto por vinte alunos - Alunos não pesquisadores.

O grupo A (alunos pesquisadores) iniciou as práticas de estudos referentes à linguagem no mês de março de 2007 até o mês de dezembro deste mesmo ano. Dentre as práticas de estudos estão: (a) a coleta de falas; (b) a transcrição das falas coletadas; (c) a análise das falas coletas; (d) a análise das regras da Gramática Tradicional; (e) a comparação das falas coletadas com as regras da Gramática Tradicional; (f) os resultados da comparação. Isto é, os alunos coletaram a fala de cinquenta habitantes do município de São Francisco do Sul - (SC). Os habitantes tinham idade entre 21 e 57 anos, graus de escolaridade variados, sexo masculino e feminino e pertenciam a diferentes classes sociais. Após a coleta, os alunos se reuniam para realizar a análise e a transcrição das falas coletadas que, por sua vez, eram comparadas com a Gramática Tradicional. Debates e discussões sobre as falas coletadas e as regras impostas pela Gramática Tradicional eram atos frequentemente praticados pelo grupo. Ou melhor, as discussões e os debates realizados estavam relacionados à gramática normativa e à linguagem usada pelos falantes de São Francisco do Sul. 
Já os vinte alunos que formavam o grupo B não coletaram, não transcreveram, não analisaram falas orais e nem realizaram comparações entre a oralidade (falas coletadas) e a escrita (Gramática Tradicional), nem trabalharam em grupo, tal como os alunos do grupo A. O grupo B participou das aulas de português em que eram transmitidas noções gramaticais e também, em alguns momentos, noções de variações linguísticas. Os estudantes do grupo B não vivenciaram, não “experienciaram” a realidade, isto é, não estudaram a relação entre a variação linguística (Ex: falas coletadas - oralidade) e a Gramática Tradicional (escrita). Apenas conviveram com noções teóricas de maneira abstrata que eram transmitidas pelo professor $Y$.

Tal como abordado em momento precedente, o professor $\mathrm{Y}$ foi um agente mediador no grupo A, isto é, o professor interagiu ativamente com os alunos, discutindo, questionando, debatendo, analisando juntamente com os alunos assuntos que eram abordados durante a aula. Por meio dessa atitude o professor passou a estimular o instinto pesquisador, o senso crítico e reflexivo desses alunos. Já no grupo B, o professor atuou como um agente transmissor de conteúdos (regras gramaticais), isto é, ele não interagiu ativamente com os alunos, apenas transmitiu e explicou conteúdos.

\section{Análise dos dados - Principais resultados}

A pesquisa desenvolvida com o grupo A foi conduzida a partir dos seguintes passos:

a) $1^{\circ}$ passo: Coleta de falas de 50 habitantes do município de São Francisco do Sul (SC);

b) $\quad 2^{\circ}$ passo: Transcrição das falas coletadas;

c) $3^{\circ}$ passo: Análise e discussão das falas coletadas (o grupo analisava e discutia se as falas coletadas de dados habitantes do município de São Francisco do Sul - (SC) seguiam ou não seguiam as regras da Gramática Tradicional);

d) $4^{\circ}$ passo: Comparação - Transcrições X regras da Gramática Tradicional;

e) $5^{\circ}$ passo: Análises e debates (análises e debates concernentes aos resultados finais alcançados por meio da comparação $-4^{\circ}$ passo desta metodologia). 
Seguindo os procedimentos acima expostos, em uma única coleta de falas o grupo de alunos pesquisadores analisou que havia falta de:

a) Concordância verbal, isto é, perceberam que as pessoas enunciam frases tais como:

“[A gente fomos pra reunião]” e não “[A gente foi para a reunião]”.

b) Concordância nominal:

“[As criança são esperta]” e não “[As crianças são espertas]”.

c) Regência verbal:

“[O filho não obedece o pai]” e não “[O filho não obedece ao pai]”.

Além desses fatores acima citados, o grupo percebeu reduções e aumentos fonéticos, tal como também observou a troca de fonemas. Em virtude das análises desenvolvidas, os alunos do grupo A elaboraram um quadro fonético. A seguir, no quadro (1), apresentam-se alguns exemplos que eles listaram:

\begin{tabular}{|c|c|}
\hline $\mathrm{L} \rightarrow \mathrm{R}$ depois de consoante & $\begin{array}{ll}\text { Ex: } & \text { probLema } \rightarrow \text { probRema* } \\
& \text { cLaro } \rightarrow \text { cRaro* } \\
& \text { CLáudio } \rightarrow \text { CRáudio* } \\
& \text { pLanta } \rightarrow \text { pRanta* } \\
& \text { fLauta } \rightarrow \text { fRauta* }\end{array}$ \\
\hline $\mathrm{R} \rightarrow \#$ final de palavra & 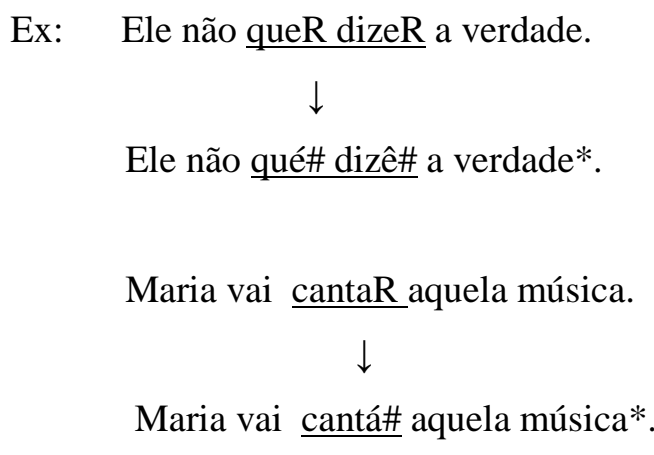 \\
\hline $\mathrm{LH} \rightarrow \mathrm{I}$ entre duas vogais & $\begin{array}{ll}\text { Ex: } & \text { muLHer } \rightarrow \text { muIé* } \\
& \text { meLHor } \rightarrow \text { meIó* }\end{array}$ \\
\hline $\mathrm{L} \rightarrow \mathrm{R}$ final de sílaba & Ex: $\quad$ aLmoço $\rightarrow$ aRmoço* \\
\hline
\end{tabular}




\begin{tabular}{|c|c|c|c|}
\hline & & $\begin{array}{l}\text { caLça } \rightarrow \text { caRça* } \\
\text { baLde } \rightarrow \text { baRde* } \\
\text { maLvado } \rightarrow \text { maRvado* }\end{array}$ & \\
\hline $\begin{array}{l}\mathrm{I} \rightarrow \#(\text { (em ditongo }) \\
\mathrm{U} \rightarrow \#(\text { (em ditongo })\end{array}$ & Ex: & $\begin{array}{l}\mathrm{I} \rightarrow \# \text { (em ditongo) } \\
\text { queIjo } \rightarrow \text { que\#jo* } \\
\text { beIjo } \rightarrow \text { be\#jo* } \\
\text { caIxa } \rightarrow \text { ca\#xa* }\end{array}$ & $\begin{array}{c}\mathrm{U} \rightarrow \# \text { (em ditongo) } \\
\text { troUxa } \rightarrow \text { tro\#xa* } \\
\text { oUtro } \rightarrow \text { o\#tro* } \\
\text { oUro } \rightarrow \text { o\#ro* }\end{array}$ \\
\hline $\mathrm{L} \rightarrow \#$ final de palavra & Ex: & pessoaL $\rightarrow$ pessoá $^{*}$ & \\
\hline $\mathrm{D} \rightarrow \#$ depois de nasal & Ex: & $\begin{array}{l}\text { andanDo } \rightarrow \text { andan\#o* } \\
\text { cantanDo } \rightarrow \text { cantan\#o* }\end{array}$ & \\
\hline $\mathrm{R} \rightarrow \#$ depois de consoante & & $\begin{aligned} \text { pRoblema } & \rightarrow \text { p\#oblema* } \\
\text { pRivilégio } & \rightarrow \text { p\#ivilégio* }\end{aligned}$ & \\
\hline $\mathrm{S} \rightarrow \#$ final de palavra & Ex: & $\begin{array}{l}\text { vamoS } \rightarrow \text { vamo\#* } \\
\text { encontramoS } \rightarrow \text { encontramo\#* }\end{array}$ & \\
\hline $\begin{array}{l}\# \rightarrow \text { I depois de consoante final } \\
\text { de sílaba }\end{array}$ & & $\begin{array}{l}\text { ad\#vogado } \rightarrow \text { ad I vogado* } \\
\text { ap\#to } \rightarrow \text { ap I to* }\end{array}$ & \\
\hline $\mathrm{L} \rightarrow \mathrm{U}$ final de síbala & Ex: & $\begin{array}{l}\text { BrasiL } \rightarrow \text { BrasiU* } \\
\text { goL } \rightarrow \text { goU* } \\
\text { soL } \rightarrow \text { soU* }\end{array}$ & \\
\hline $\begin{array}{l}\mathrm{L} \rightarrow \mathrm{LH} \text { diante de ditongo } \\
\text { iniciado por }[\mathrm{i}]\end{array}$ & Ex: & famíLia $\rightarrow$ famíLHa* & \\
\hline $\begin{array}{l}\text { I acréscimo (aparência de } \\
\text { semivogal) }\end{array}$ & Ex: & $\begin{array}{l}\text { caranguejo } \rightarrow \text { carangueIjo* } \\
\text { azulejo } \rightarrow \text { azuleIjo* }\end{array}$ & \\
\hline $\mathrm{O} \rightarrow \mathrm{U}$ final de sílaba & Ex: & $\begin{array}{l}\text { asfaltO } \rightarrow \text { asfaltU* } \\
\text { campO } \rightarrow \text { campU* } \\
\text { saltO } \rightarrow \text { saltU* }\end{array}$ & \\
\hline $\mathrm{E} \rightarrow \mathrm{I}$ final de sílaba & & $\begin{array}{l}\text { elE } \rightarrow \text { elI* } \\
\text { existE } \rightarrow \text { existI* } \\
\text { vestE } \rightarrow \text { vestI* }\end{array}$ & \\
\hline \multicolumn{4}{|c|}{$\begin{array}{l}\text { Observação: O grupo A, por meio da pesquisa que desenvolveu, deduziu que as palavras que } \\
\text { apresentam o asterisco }(*) \text { são formas que ocorrem na oralidade, na fala. Já as formas sem o asterisco } \\
(*) \text { são formas padronizadas da escrita. }\end{array}$} \\
\hline
\end{tabular}

Quadro (1): Este quadro desenvolvido pelos alunos está baseado nos estudos de: (LEMLE, Mirian. Guia teórico do alfabetizador. São Paulo: Ática, 2000). 
Esta estratégia de ensino estimulou o instinto pesquisador, reflexivo e analítico dos alunos do grupo A. Os alunos desse grupo passaram a explicar os fenômenos linguísticos com os quais se deparavam baseando-se tanto nas regras gramaticais ${ }^{6}$ quanto em fatores culturais e sociais. A partir daí perceberam que no pequeno município de São Francisco do Sul (SC) existe uma grande variedade linguística. Concluíram que ninguém falará do jeito que escreve, que cada pessoa se comunicará de acordo com o grupo social no qual está inserido.

Nesse grupo (A), o professor Y desempenhou o papel de mediador entre o aluno e o meio. O professor $\mathrm{Y}$ criou uma situação desafiadora em um contexto significativo para o aluno, permitindo que o educando por si só busque, explore várias possibilidades para resolver o desafio (passos acima apresentados), mesmo que sejam possibilidades contraditórias ou falsas. As contradições, que fazem parte do processo de aprendizagem foram no decorrer das aulas esclarecidas, exploradas, discutidas, em grupo, com a presença do professor. Nesse caso, o professor Y proporcionou ao aluno discussões, experiências que auxiliaram no desenvolvimento do raciocínio abstrato (por exemplo, regras gramaticais da Língua Portuguesa) em algo concreto (por exemplo, regras gramaticais da Língua Portuguesa em uso) (LAKOMY, 2003). Essa prática docente desenvolvida pelo professor Y faz lembrar a perspectiva construtivista de Piaget (FERREIRO, 2001; FLAVELL, J. H.; MILLER, P. H., 1999; GOULART, 1997; LAKOMY, 2003; MATUI, 1996; MOLL, 1997; PALANGANA, 1998; SANTANA, S. M.; ROAZZI, A.; DIAS, M. G. B. B, 2006; PIAGET, 1980, 1988, 1990; POZO, 1998). Pois,

a concepção construtivista não é, num sentido estrito, uma teoria, mas um referencial explicativo que interpreta o processo de ensino-aprendizagem como um processo social de caráter ativo em que o conhecimento é fruto da construção pessoal do aluno, construção essa mediada pelo professor [...] (LAKOMY, 2003, p. 33).

O grupo B não coletou falas, não transcreveu e nem analisou falas coletadas, não comparou falas coletadas com as regras da gramática padrão. O professor $\mathrm{Y}$ apenas transmitiu, de maneira impositiva, a esses alunos noções gramaticais normativas e, em determinados momentos, noções de variedades linguísticas. Ou seja, a palavra do professor era entendida pelos alunos desse grupo como sendo a única palavra válida, a única palavra correta. Então, percebeu-se que durante as aulas os alunos do grupo B aprendiam de maneira mecânica, prendendo-se apenas ao que o professor transmitia, sem questionarem, comentarem 
de maneira crítica os assuntos apresentados, certamente isso se deve ao fato que esses alunos não trabalharam de forma empírica, não observaram, não analisaram as regras gramaticais normativas e nem as variedades linguísticas de forma concreta, apenas “teórica” e “abstrata”. Não realizaram discussões e estudos em grupo. Nesse caso, observou-se que os alunos do grupo B entendiam que a disciplina da Língua Portuguesa não passava de um conjunto de regras que só seria aprendido se fosse memorizado. Chegou-se a essa conclusão observando os alunos em sala de aula nos momentos em que o professor Y transmitia os conteúdos. Essa estratégia e/ou metodologia de observação já fora utilizada pelo próprio Piaget ao desenvolver seus estudos sobre a aprendizagem e o desenvolvimento cognitivo da criança (FERREIRO, 2001; FLAVELL, J. H.; MILLER, P. H., 1999; LAKOMY, 2003; SANTANA, S. M.; ROAZZI, A.; DIAS, M. G. B. B, 2006; PIAGET, 1980, 1988, 1990).

Diante desses dois grupos é possível concluir, de acordo com Carvalho (2008, p. 02), que o professor deve proporcionar uma aprendizagem significativa ao aluno, só assim terá resultados positivos.

Nesse caso, com base na abordagem de Lakomy (2003, p. 37) sobre classes tradicionais e classes construtivistas, contrastando os dois grupos: A e B, conclui-se que,

\begin{tabular}{|c|c|}
\hline $\begin{array}{l}\text { GRUPO “B” - A aprendizagem não é } \\
\text { significativa ao aluno. }\end{array}$ & $\begin{array}{l}\text { GRUPO “A” - Aulas planejadas. A } \\
\text { aprendizagem é significativa ao aluno. }\end{array}$ \\
\hline $\begin{array}{l}\text {-O professor vê o aluno como aquele que } \\
\text { só recebe informações. O professor } \\
\text { transmite os conteúdos e, algumas vezes, } \\
\text { "impõem" as informações ao aluno. }\end{array}$ & $\begin{array}{l}\text {-O professor vê o aluno como um agente } \\
\text { ativo e como um pensador. O professor age, } \\
\text { quase sempre, de maneira interativa, sendo } \\
\text { o mediador entre o meio e os alunos. Os } \\
\text { professores buscam, estimulam e valorizam } \\
\text { as dúvidas dos alunos. }\end{array}$ \\
\hline $\begin{array}{l}\text { - Os educadores buscam as respostas certas } \\
\text { para avaliar a aprendizagem do aluno. }\end{array}$ & $\begin{array}{l}\text { •Os professores buscam o que o aluno } \\
\text { compreende e conhece para entender suas } \\
\text { concepções atuais, tendo como objetivo usá- } \\
\text { las nas lições ulteriores. }\end{array}$ \\
\hline $\begin{array}{l}\text { - Os alunos trabalham individualmente, sem } \\
\text { compartilhar conhecimentos. }\end{array}$ & $\begin{array}{l}\bullet \text { Os alunos trabalham em grupo, } \\
\text { compartilhando conhecimentos. }\end{array}$ \\
\hline
\end{tabular}

Quadro (2): Grupo A \& Grupo B. Quadro baseado em Lakomy (2003, p. 37). 


\section{Considerações finais}

Através desta estratégia de ensino-aprendizagem (cf. seções 2 e 3 deste artigo), percebeu-se que a coleta de falas, a transcrição e análise dessas falas e sua respectiva comparação com a gramática padrão, o reconhecimento das variedades linguísticas são questões fundamentais para que os alunos compreendam a Gramática Tradicional e as variedades linguísticas existentes no mundo social.

É de suma relevância que o estudante e frequentador das aulas de língua portuguesa perceba que a língua não é apenas a gramática apresentada nos livros didáticos. É importante que o aluno compreenda que a língua é muito mais que a Gramática Tradicional apresentada nos manuais de gramática, é extremamente importante que ele entenda que a língua é viva, transforma-se e modifica-se.

Tomando por base o grupo de alunos pesquisadores do $3^{\circ}$ ano do Ensino Médio - (grupo A), pode-se afirmar que esta estratégia de ensino-aprendizagem apresentada neste artigo permitiu que os alunos conhecessem as variedades linguísticas existentes e por motivação pessoal tentaram compreendê-las sem preconceito. Por isso, é necessário que o professor de língua portuguesa não só exponha e imponha regras gramaticais nas aulas de português, mas trabalhe com diferentes estratégias de ensino-aprendizagem que estimulem o querer estudar, o querer pesquisar/investigar. É de extrema importância que os futuros profissionais (professores) desta área de ensino sejam orientados, ao menos durante os cinco anos em que frequentam o curso de formação superior, que estratégias de ensino-aprendizagem diferenciadas, planejadas, que correspondam à realidade do aluno são necessárias e contribuem para uma boa aprendizagem, isto é, uma aprendizagem que tenha sentido para o aluno. Como afirma Libâneo (1992, p. 71), “os conhecimentos teóricos e metodológicos, assim como o domínio dos modos do fazer docente (grifo meu), propiciam uma orientação mais segura para o trabalho profissional do professor”.

Porém, chega-se ao fim deste artigo, argumentando que, embora vários linguistas e estudiosos, tais como, Almeida Filho (2005), Andrade (2004), Barcelos (2004), Carvalho (2008), Geraldi (1996), Luft (2003), Lemle (1995), Marcuschi (1997, 2001), Perini (2003), 
Possenti (1996), Santos (2004), Silva (2005, 2007), Suassuna (1995), Travaglia (1996, 1998, 2000, 2003), entre tantos outros aqui não citados, tenham desenvolvido e continuam desenvolvendo pesquisas, estudos, assim como, apresentam reflexões sobre o ensino e a aprendizagem da língua materna e, alguns também, da língua estrangeira, ainda não se alcançou uma prática docente totalmente eficaz e diferente no ensino-aprendizagem, embora esforços de muitos profissionais e estudiosos da área da educação têm contribuído bastante nesta busca incessante por uma prática docente que torne a aprendizagem significativa ao aluno.

\section{Referências Bibliográficas}

ALMEIDA FILHO, J.C.P. Lingüística Aplicada: Ensino de Línguas e Comunicação. Campinas,SP: Pontes Editores e Arte Língua, 2005.

ANDRADE, A.A.C. Crenças de alunos e professores da escola pública sobre a aprendizagem de língua na escola regular. Dissertação (Mestrado em Estudos da Linguagem), Universidade Federal do Rio Grande do Norte, Natal, 2004.

BAGNO, Marcos. Dramática da língua da língua portuguesa: tradição gramatical, mídia \& exclusão social. São Paulo: Loyola, 2000.

Português ou brasileiro? Um convite à pesquisa. 2. ed. São Paulo: Parábola, 2001.

.Preconceito lingüístico. 3. ed. São Paulo: Loyola, 1999.

BARCELOS, A.M.F. Crenças sobre aprendizagem de línguas, lingüística aplicada e ensino de línguas. Linguagem \& Ensino, v.7, n.1, p.123-156, 2004. 
BARCELOS, A.M.F.; VIEIRA-ABRAHÃO, M.H. (Org.). Crenças e Ensino de Línguas: foco no professor, no aluno e na formação de professores. Campinas, SP: Pontes, 2006. p.15-42.

BECHARA, Evanildo. Ensino da gramática. Opressão? Liberdade? 4. ed. São Paulo: Ática, 1989.

CARVALHO, Adriano de Oliveira. A educação lingüística e a pedagogia da leitura: contribuições para o ensino. PUC/SP 2008 - Programa de Pós Graduação em Língua Portuguesa. Disponível em: <http:/www.fflch.usp.br-eventos/simelp/new/pdf/slp41/01.pdf>. Acesso em: 31 de maio de 2009.

FERREIRO, E. Atualidades de Jean Piaget. Porto Alegre: Artmed, 2001.

FLAVELL, J. H.; MILLER, P. H. Desenvolvimento Cognitivo. São Paulo: Artmed, 1999.

GARBUIO, L. M Revelação e origens de crenças da competência implícita de professores de língua inglesa. Dissertação (Mestrado em Lingüística Aplicada), Instituto de Estudos da Linguagem, UNICAMP, Campinas, 2005.

GERALDI, J. W. Linguagem e ensino. Campinas: Mercado de Letras, 1996.

GIL, G.; RAUBER, A.S.; CARAZZAI, M.M.; BERGSLEITHNER, J. (Org.) Pesquisas qualitativas no ensino e aprendizagem de língua estrangeira: a sala de aula e o professor. Florianópolis: UFSC, 2005.

GOULART, I. (Org.). Piaget: experiências básicas para utilização do professor. Rio de Janeiro: Vozes, 1997. 
LAKOMY, A. M. Teorias cognitivas da aprendizagem. Curitiba: IBPEX, 2003.

LEITE, Cília C. Pereira (Madre Oliveira) e SILVEIRA, Regina Célia P. A gramática portuguesa: na pesquisa e no ensino. São Paulo: Cortez, 1980.

LEMLE, Mirian. Guia teórico do alfabetizador. São Paulo: Ática, 2000.

LIBÂNEO, José Carlos. Didática. São Paulo:Cortez, 1992.

LYONS, John. As idéias de Chomsky. São Paulo: Cultrix, 1973.

LUFT, P. C. Língua \& Liberdade: por uma nova concepção da língua materna. São Paulo: Ática, 2003.

MANDRIK, David e FARACO, A. Prática de redação para estudantes universitários. 9. ed. Petrópolis: Vozes, 2001.

MARCUSCHI, L. A. A concepção de língua falada nos manuais de português de $1^{\circ}$ e $2^{\circ}$ graus: uma visão crítica. Trabalhos em Lingüística Aplicada, Campinas, SP: UNICAMP/IEL, n. 30, 1997.

Da fala para a escrita: atividades de retextualização. 2. ed. São Paulo: Cortez, 2001.

MATUI, J. Construtivismo: teoria sócio-construtivista aplicada ao ensino. São Paulo: Moderna, 1996.

MOLL, L. Vygotsky e a educação. Porto Alegre: Artes Médicas,1997. 
MUSSALIM, Fernanda; BENTES, Anna Christina. Introdução à lingüística: Domínios e fornteiras. V. II. São Paulo: Cortez, 2001.

ORLANDI, Eni Pulcinelli. A linguagem e seu funcionamento: as formas do discurso. 2. ed. Campinas, São Paulo: Pontes, 1987.

PALANGANA, I. Desenvolvimento e aprendizagem em Piaget e Vygotsky. São Paulo: Plexus, 1998.

PERINI, M. A. Sofrendo a gramática: ensaios sobre a linguagem. São Paulo: Ática, 1997. Gramática descritiva do português. 4. ed. São Paulo: Ática, 2003.

PIAGET, J. Para aonde vai a educação? Rio de Janeiro: José Olympio, 1980. . A construção do real na criança. Rio de Janeiro: Zahar, 1988. . Linguagem e pensamento da criança. Rio de Janeiro: Fundo de Cultura, 1990.

POSSENTI, S. Por que (não) ensinar gramática na escola. Campinas: Mercado de letras, 1996.

POZO, J. Teorias cognitivas da aprendizagem. Porto Alegre: Artes Médicas, 1998.

ROCHA, C.H. Provisões para Ensinar LE no Ensino Fundamental de $1^{a}$ a $4^{a}$ Séries: dos Parâmetros Oficiais e Objetivos dos Agentes. Dissertação (Mestrado em Lingüística Aplicada), Instituto de Estudos da Linguagem, UNICAMP, Campinas, 2006. 
SANTANA, S. M.; ROAZZI, A.; DIAS, M. G. B. B. Paradigmas do desenvolvimento cognitivo: uma breve retrospectiva. Estudos de Psicologia, 2006, pp. 71-78.

SANTOS, J. S. dos. Letramento, variação lingüística e ensino de português. Linguagem em (Dis)curso, Tubarão, v. 5, n. 1, p. 119-134, 2004.

SILVA, K. A. Crenças e aglomerados de crenças de alunos ingressantes em Letras (Inglês). Dissertação (Mestrado em Lingüística Aplicada), Instituto de Estudos da Linguagem, UNICAMP, Campinas, 2005.

SILVA, K. A. da. Crenças sobre o ensino e aprendizagem de línguas na Lingüística Aplicada: um panorama histórico dos estudos realizados no contexto brasileiro. Linguagem \& Ensino,v.10, n.1, p.235-271, jan./jun. 2007.

SUASSUNA, L. Ensino de Língua Portuguesa: uma abordagem pragmática. Campinas, SP: Papirus, 1995.

TRAVAGLIA, L. C. Gramática e interação: uma proposta para o ensino de gramática no $1^{\circ}$ e $2^{o}$ graus. São Paulo: Cortes, 1996.

Universidade e educação lingüística. Revista da Unicsul: A universidade do século XXI - desafios e perspectivas. São Paulo: Unicsul, ano 3, n. 4, p. 85-98, ago. 1998.

A sistematização do ensino de gramática em atividades de gramática reflexiva e outras. In: BASTOS, N. B. (Org.). Discutindo a prática docente em Língua Portuguesa. São Paulo: IP-PUC/SP, p. 59-70, 2000. 


\section{Notas de rodapé}

${ }^{1}$ Investigação iniciada em 2002 através do Projeto de Iniciação Científica - "Linguagem Padrão: uma forma de subjugar” - desenvolvido na Universidade da Região de Joinville. Desde então esta pesquisa vem sendo desenvolvida e atualizada.

2 “X” - Assim será denominada a escola pública onde foi realizada a pesquisa em 2007.

${ }^{3}$ Para saber mais sobre o projeto confira o artigo: FOSSILE, D. K e KOERNER, R. Linguagem padrão: uma forma de subjugar. Caderno de Iniciação Científica à Pesquisa. Joinville, v. 5, p. 252-258, nov. de 2003.

${ }^{4}$ Para saber mais sobre o projeto confira o artigo: FOSSILE, D. K e CAVASSIN, R. B. Problemas de sintaxe e ortografia: análise de produções textuais do ensino fundamental e médio. Caderno de Iniciação Científica à Pesquisa. Joinville, v. 6, p. 232-236, 2004.

5 “Y” - Professor responsável pelo grupo de alunos.

${ }^{6}$ Os alunos do grupo A passaram a entender que as regras gramaticais são importantes e necessárias para que haja uma certa uniformidade linguística no mundo social. 